\title{
Article \\ Study on Effect of Leather Rigidity and Thickness on Drapability of Sheep Garment Leather
}

\author{
Hafeezullah Memon ${ }^{1, *(\mathbb{C})}$, Eldana Bizuneh Chaklie ${ }^{2}$, Hanur Meku Yesuf ${ }^{2,3(\mathbb{D})}$ and Chengyan Zhu ${ }^{1, *}$ \\ 1 College of Textile Science and Engineering, International Institute of Silk, Zhejiang Sci-Tech University, \\ Hangzhou 310018, China \\ 2 Ethiopian Institute of Textile and Fashion Technology, Bair Dar University, Bahir Dar 6000, Ethiopia; \\ elduyod@gmail.com (E.B.C.); 419005@mail.dhu.edu.cn (H.M.Y.) \\ 3 College of Textiles, Donghua University, Shanghai 201620, China \\ * Correspondence: hm@zstu.edu.cn (H.M.); cyzhu@zstu.edu.cn (C.Z.)
}

Citation: Memon, H.; Chaklie, E.B.; Yesuf, H.M.; Zhu, C. Study on Effect of Leather Rigidity and Thickness on Drapability of Sheep Garment Leather. Materials 2021, 14, 4553. https://doi.org/10.3390/ma14164553

Academic Editor: Dubravko Rogale

Received: 27 June 2021

Accepted: 12 August 2021

Published: 13 August 2021

Publisher's Note: MDPI stays neutral with regard to jurisdictional claims in published maps and institutional affiliations.

Copyright: (c) 2021 by the authors. Licensee MDPI, Basel, Switzerland. This article is an open access article distributed under the terms and conditions of the Creative Commons Attribution (CC BY) license (https:/ / creativecommons.org/licenses/by/ $4.0 /)$.

\begin{abstract}
Understanding the performance and behavior of garment leathers provides valuable inputs for the design and production of leather garments. The drape is one of the important properties associated with garment fitness quality and appeal. This study aims to show how the independent variables flexural rigidity and thickness affect the dependent variable drapability. Nowadays, studies on the drape of garment leathers are scarce. In this work, the drape coefficient (DC) was measured for sheep garment leather, which influences the garment drapability, such as flexural rigidity in the range of 9.2 to 22 and thickness in the range of 0.64 to 0.96 . The average DC was calculated in the range of 47.35 to $69.9 \%$ for the selected sheep leathers from four samples. The drapability of the garment leather was determined using the DC. Flexural rigidity and thickness have been shown to have a considerable influence on the DC, while they do bear a significant relationship to the DC. The results of this study can be used as an elementary tool for leather selection of appropriate materials for garments.
\end{abstract}

Keywords: leather; drape coefficient; leather rigidity; drapability; leather thickness

\section{Introduction}

Leathers for garments can be manufactured from almost all types of raw stock [1]. Nevertheless, the widely used raw material is sheepskins for their histological characteristics [2]. All the other skins such as goat skins, cow skins, and calf skins are also widely used, and the thickness range varies from 0.6 to $1.0 \mathrm{~mm}$ [3]. The qualities of the garment leathers are always required to be similar for their specific purpose and end use [4]. Some of the quality parameters and comfort parameters and the methodologies to be followed in leather processing are discussed below.

There are different properties that garment leather should have, such as lightweight, fastness (to rub, light, wash, etc.), durability, drapability, etc. [5]. On the other hand, the drape is the most significant garment feature, since it contributes to wear comfort [6]. This feature refers to the leather's capacity to fall in a similar manner to textile and conform to the body's shape when worn [7]. It is an inherent and essential quality for any leather to be called garment leather [8]. Whenever leather is having a cloth-like fall, it is said to have the quality of drape. The leathers require being as flexible as cloth with the utmost degree of softness without any firmness. Significantly less filling and more fat-liquoring will increase the drape quality of the leather [9]. Leather drapability is a morphological property that occurs when leather is hung down for gravity reasons. It is one of the essential indicators when measuring close-fitting clothing [6]. Therefore, good drapability is necessary for garment leathers [10]. The drapability of leather is closely related to the clothing classification [11]. There are two ways to examine leather drapes: using your senses or using testers (commonly used) [12]. A circular sample with a specific area is 
placed on a sample clamping plate, with their centers overlapping, causing the drape sample to droop along with the circular plate due to gravity [13].

According to the research done to date [6], the leather drape is determined mainly by the leather thickness, and rigidity/stiffness properties, with leather tensile and weight also of some importance. Therefore, to be able to determine the leather drape requires that the precise relationship between leather drape and leather rigidity /stiffness and thickness is known and that their effects on the leather physical property are also known [14]. In addition, leather garment drapes will be considered from the drape coefficient (DC) perspective only [15]. The bending length of the leather can determine the rigidity of the leather. For a better knowledge of drapability, it is essential to look into and grasp the fundamental bending behavior of leather [15]. The DC determines drapability; if the DC becomes between 30 and 80, the leather could be used for apparel [16]. It is well known that there are different hierarchical levels of leather within leather attach, and this is especially true for leather that has not been staked or fat-liquored [17]. The rigidity and stiffness of leather can be related to its bending length, as reported by [15]. The other main thing that must be noticed in the selection of leather is the effect of leather tanning material on the leather thickness and stiffness property [18]. Vegetable tanning material gives more thickness, fullness, roundness, etc. [19], whereas chrome gives empty, flexible, and soft leather [20].

This research aimed to show the actual effects of thickness and stiffness variability on leather drape quality difference by taking different leathers to measure all variables and analyze the result. Herein, leathers with vegetable and chrome tanned or re-tanned to reach each factor level in one sample leather have been studied. This helps set the optimum levels of independent variables thickness and flexural rigidity and optimize dependent variable drapability.

\section{Experimental}

\subsection{Materials}

Four types of sheep leather for the garment were reached from the EiTEX leather laboratory store. Among them, Leather 1 is chrome tanned leather; Leather 2 is vegetable tanned chrome re-tanned; Leather 3 has lower thickness higher rigidity; this leather is chrome tanned, vegetable re-tanned type of leather, and Leather 4 is vegetable-tanned.

Table 1 shows standard and measured values of independent variables (thickness and rigidity) that influence the dependent variable drape coefficient of the garment. If measured values from specimens in between their minimum and maximum limit levels of Indian standard IS 6490, the sheep leather samples can be used for apparel applications. Therefore, the specimens used for this research can be used for apparel applications.

Table 1. Variables and their levels.

\begin{tabular}{ccc}
\hline Variables & Standard & Actual Measured Values \\
\hline Thickness $(\mathrm{mm})$ & $0.6-1.0$ & $0.64-0.96$ \\
\hline Rigidity/Stiffness $(\mathrm{mN} / \mathrm{mm})$ & $90-125$ & $94-124$ \\
\hline Drape Coefficient $(\%)$ & $30-80$ & $48-64$ \\
\hline
\end{tabular}

\subsection{Method}

Factorial designs are commonly employed in engineering experiments involving two factors where the combined effect of the factors on a response must be studied [21]. A factor's effect is defined as the change in reaction caused by a change in the factor's level [22]. The effects of leather thickness and rigidity on the separation force are next investigated using a factorial design [22]. A factorial design is commonly used to investigate the impacts of corresponding components, material qualities, and establish the best study circumstances, among other things. This includes ANOVA, regression analysis, model significance, model adequacy, and fit statistics using design expert software. 


\subsection{Research Design}

This study follows an experimental research design (Full Factorial Design) because experimental research follows a scientific approach, where it includes a hypothesis, a variable that the researcher can manipulate, and the variable that can be evaluated, calculated, and compared. The study aims to distinguish the optimal effect of leather rigidity and thickness on garment drape property to select the appropriate leather property, which gives better results to recognizers obtained through experimental studies. These also required extensive experimentation, which involves examining the leather's physical properties through laboratory experimentation and giving better results, showing the effect of factors on leather drapes.

This testing works together with laboratory assistants. The conclusion of the causeand-effect research reveals that two elements directly impact the leather's drapability. They are flexural rigidity and thickness of the material. Flexural rigidity is a measure of the stiffness of leather and is related to the bending length of the specimen due to gravitational force. Thickness is the distance through the leather, as distinct from width or height [23]. In a factorial experiment, these variables are assigned as independent variables.

Technical experience and understanding of operating and various experiments are required to set the factors in this experiment. It is known from their experiences that if all parameters are set too low, the drapability increases [24]. However, if these parameters are set too high, the drapability will be low because the DC will also be high. To avoid unfavorable outcomes in the experiment, proper samples of garment leather with the same thickness and rigidity are necessary. The expected ranges of factors are presented based on the experiment. Since all factors have two levels, a 22 factorial design is used. Each run is performed with three replicates at random, and the data are assessed at a significant level of 1 to achieve a very low type III error.

\subsection{Thickness}

The thickness of samples was measured with a digital thickness Gauge TF121C as leather has different thicknesses in different portions such as the shoulder (the thickest part), butt (the thicker area next to the shoulder area), belly (poor portion), and shank. Therefore, each leather sample was measured fifteen times to get a more accurate measurement, and finally, we used the average lower result of a thickness as a minimum and the average higher result as a maximum level.

Table 2 shows that the two samples (L1 and L3) have the same thickness and rigidity level, while the other two samples (L2 and L4) have the same thickness and rigidity levels. Due to these reasons, average measurements of two leather kinds, either L1 and L3 or L2 and L4, were used for minimum and maximum thickness levels.

Table 2. Measurements of leather thickness in $\mathrm{mm}$.

\begin{tabular}{cccccccccccccccccc}
\hline Samples & $\mathbf{1}$ & $\mathbf{2}$ & $\mathbf{3}$ & $\mathbf{4}$ & $\mathbf{5}$ & $\mathbf{6}$ & $\mathbf{7}$ & $\mathbf{8}$ & $\mathbf{9}$ & $\mathbf{1 0}$ & $\mathbf{1 1}$ & $\mathbf{1 2}$ & $\mathbf{1 3}$ & $\mathbf{1 4}$ & $\mathbf{1 5}$ & Average \\
\hline L1 & 0.75 & 0.62 & 0.58 & 0.61 & 0.89 & 0.63 & 0.54 & 0.55 & 0.56 & 0.57 & 0.67 & 0.58 & 0.65 & 0.69 & 0.65 & 0.635 & 0.95 \\
\hline L2 & 0.96 & 0.93 & 0.99 & 1.07 & 0.95 & 1.31 & 0.96 & 1.05 & 0.99 & 0.85 & 0.82 & 0.93 & 0.88 & 0.90 & 0.87 & 0.962 \\
\hline L3 & 0.71 & 0.68 & 0.59 & 0.60 & 0.80 & 0.65 & 0.55 & 0.54 & 0.61 & 0.58 & 0.65 & 0.58 & 0.65 & 0.59 & 0.77 & 0.6366 \\
\hline L4 & 0.92 & 0.97 & 0.99 & 1.0 & 0.93 & 1.09 & 0.95 & 1.15 & 0.95 & 0.92 & 0.93 & 0.88 & 0.94 & 0.91 & 0.851 & 0.9601 \\
\hline
\end{tabular}

\subsection{Bending Length}

Bending length is the ability of the leather that can be bent somewhere [25]. The Shirley stiffness tester, which comprises a platform with smooth low friction and flat surfaces, was used to measure the bending length of samples. Specimens are made from sheep leather. Three specimens were cut from four kinds of leather $\left(2.5 \times 21.5 \mathrm{~cm}^{2}\right)$. 


\subsection{Flexural Rigidity}

Flexural rigidity is a measure of the stiffness of leather and is related to the bending length of the specimen due to gravitational force [26]. It is usually attributed to the rigidity of collagen fibers in leather [27]. Flexural rigidity was determined according to the Indian standard IS 6490 test method [28]. The samples of dimensions $2.5 \times 25 \mathrm{~cm}^{2}$ were cut in parallel directions to the backbone of the leather, considering the size of the leather. The rectangular pieces were shorter in length than the specimen length specified in the standard, as it has been observed earlier that the deviation in the length of the samples up to $100 \mathrm{~mm}$ does not influence the flexural rigidity. The length of the slacker part of each sample (L) was measured with each side up, first at one end and then at the other, using the constant angle method. The mean value of $\mathrm{L}$ was measured for flexural rigidity $(\mathrm{G})$ calculation [27], as is shown below in Equation (1).

$$
\mathrm{G}=\mathrm{W} \times(\mathrm{L})^{3}
$$

where:

$\mathrm{W}=$ weight per unit area of leather $\mathrm{mN} / \mathrm{mm}$

Weight of the leather $=$ mass $(\mathrm{g})^{*}$ gravity in $\mathrm{m} / \mathrm{s}^{2}$

$\mathrm{L}=$ Bending length in $\mathrm{mm}$

$\mathrm{G}=$ Flexural rigidity in $\mathrm{mN} / \mathrm{mm}$

As shown in Table 3, L1 and L3, L2 and L4 have very similar thickness measurement results and took their result as an average minimum and maximum levels. As calculated, L1 and L2 have lower related rigidity, and L3 and L4 have related higher results, which means:

Table 3. Flexural rigidity of sample leathers.

\begin{tabular}{cc}
\hline Sample Leathers & Flexural Rigidity (G) in $\mathbf{~ N} / \mathbf{m m}$ \\
\hline L1 & 93.96 \\
\hline L2 & 94.013 \\
\hline L3 & 124.419 \\
\hline L4 & 124.55 \\
\hline
\end{tabular}

L1 has a lower thickness, lower rigidity, chrome-tanned.

L2 has a higher thickness, lower rigidity, vegetable tanned, and chrome re-tanned leather.

L3 has lower thickness higher rigidity; this leather is chrome tanned and vegetable re-tanned leather.

L4 has a higher thickness, higher rigidity, and is vegetable-tanned.

Vegetable tanning material gives more thickness, fullness, roundness, etc., whereas chrome gives empty and soft leather.

\subsection{Drapability}

Leather drapability, according to research, is a morphological property that occurs when leather is hung down for gravity [15]. It is one of the essential indicators when measuring close-fitting clothing [29]. The classification of leather as a garment, glove, upper, and so on has a strong influence on its drapability.

There are two ways to examine leather drapes: using your senses or using testers (commonly used). A circular sample with a specific area is placed on a sample clamping plate, with their centers overlapping, causing the drape sample to droop along with the circular plate due to gravity [13].

The drape sample is projected onto a white sheet, and light is used to create the draped figure of the sample, which may be obtained by a shaded area on the ring paper that represents leather drapability. The relevant indexes such as the DC can be obtained by weighing the ring paper and calculating the cut-shaded area. DC is commonly used to assess the 
drapability of leather and can be calculated in percentage as $\mathrm{DC}=\left[\left(\mathrm{W}_{2} / \mathrm{W}_{1}\right) * 100\right.$ percent $]$, which is the projected area ratio to the original area; where $W_{1}=$ total weight of the ring paper (original area) and $W_{2}=$ weight of the shaded area of the ring paper (projected area).

The DC increases as the stiffness of the leather increases and vice versa [30]; thus, the drapability of leather by looking at the drape wave number and amplitude can be estimated. Three samples, each with a diameter of $30 \mathrm{~cm}$ and no crease on the surface, are prepared. Each sample should have two sides labeled " $a$ " and " $b$ ", respectively. Three samples, each with a diameter of $30 \mathrm{~cm}$ and no crease on the surface, are prepared.

\section{Results and Discussion}

The DC and drapability of the material have an inverse relationship. As the DC becomes large, the drapability of the leather will decrease. As a standard, the garment leather drape should become between the accepted ranges 30-80, where DC below 30 is very limp leather and better to use for very small goods. The DC above 80 is very stiff leather, better to use for upper and safety gloves. The DC largely depends upon the flexural rigidity and thickness of the leather. The DC of sheep garment leather in different levels of the two factors is shown above. As the ANOVA indicates, all factors and their interactions are significant. The DC property between 47.75 and 69.9 largely depends on the thickness of the material. The thickness influences are significantly greater than the flexural rigidity value influences ranging from 94 to 124 sheep garment kinds of leather.

\subsection{Drape Coefficient vs. Thickness}

The thickness of an object is defined as the three descriptive measurements: height, width, and length. The thicknesses of the leathers were measured using a digital thickness tester. The design expert software analysis based on the given data shows thickness on leather drapability. Hence, as a thickness becomes higher, it leads to a higher DC. However, higher thickness in the garment, due to its resulting bulkiness, is often not preferred. The goal of this research was to minimize the thickness to optimize variables.

\subsection{Drapability vs. Flexural Rigidity}

Flexural rigidity is a measure of leather stiffness and is related to the bending length of the specimen. It is usually attributed to the rigidity of the collagen fibers in the leather. The flexural rigidity of garment sheep garment leathers was measured in parallel to the backbone direction. It is seen that there is a significant difference in the flexural rigidity values measured in the two levels ranging from 94 to 124 on DC results between 47 and 69. The DC and flexural rigidity have a positive or direct relationship. These values are significant. As the values of flexural rigidity become high, the DC will be higher, and the drapability will be lower. The plot of DC versus flexural rigidity (calculated from bending length values) reveals that there is a significant change.

\subsection{Analysis of the Outcome}

All key components and the interaction effect have a substantial impact on drapability, according to the analysis of variance (ANOVA), as discussed in Table 4. The 402.60 Model F-values indicate that the model is significant. An F-value of this magnitude has a $0.01 \%$ chance of occurring due to noise. While the F-values of rigidity, thickness, and interaction of both factors are significant, the F-values of rigidity, thickness, and interaction of both factors are not. Model terms with P-values less than 0.0500 are significant. Model reduction may improve the model if there are many nominal model terms (not including those required to support hierarchy).

The final model's projected $\mathrm{R}^{2}$ of $0.9852(98 \%)$ agrees reasonably well with the adjusted $\mathrm{R}^{2}$ of $0.9910(99 \%)$; that is, the difference is less than $0.2(20 \%)$, implying that the final models can forecast with unpredicted changes of less than $2 \%$, where enough precision measures the signal-to-noise ratio, as it is shown in Table 5. 
Table 4. ANOVA for the factorial model of choice.

\begin{tabular}{ccccccc}
\hline Source & $\begin{array}{c}\text { Sum of } \\
\text { Squares }\end{array}$ & $\begin{array}{c}\text { Degree of } \\
\text { Freedom }\end{array}$ & $\begin{array}{c}\text { Square of } \\
\text { Mean }\end{array}$ & F-Value & $p$-Value & Remarks \\
\hline Model & 770.14 & 3 & 256.71 & 402.60 & $<0.0001$ & Significant \\
\hline $\begin{array}{c}\text { A-Rigidity } \\
(\mathrm{mN} / \mathrm{mm})\end{array}$ & 170.93 & 1 & 170.93 & 268.07 & $<0.0001$ & \\
\hline B-Thickness $(\mathrm{mm})$ & 546.08 & 1 & 546.08 & 856.41 & $<0.0001$ & \\
\hline $\mathrm{AB}$ & 53.13 & 1 & 53.13 & 83.32 & $<0.0001$ & \\
\hline Pure Error & 5.10 & 8 & 0.6376 & & & \\
\hline Cor Total & 775.24 & 11 & & & & \\
\hline
\end{tabular}

Table 5. Fit statistics for the model.

\begin{tabular}{cccc}
\hline Std. Dev. & 0.7985 & $\mathrm{R}^{2}$ & 0.9934 \\
\hline Mean & 56.60 & ${\text { Adjusted } \mathrm{R}^{2}}^{2}$ & 0.9910 \\
\hline C.V. $\%$ & 1.41 & Predicted $\mathrm{R}^{2}$ & 0.9852 \\
\hline & & Adequate Precision & 45.6374 \\
\hline
\end{tabular}

\subsection{Model Adequacy Checking}

Before moving on to the next step, the residuals of the final models must be verified to see if they meet three criteria: first, they must be normally distributed; second, their variance must be constant; and third, they must be independent of the components. The normal probability plot of the residuals, the plot of residuals vs. fitted values, and the plot of residuals versus predicted values of the final models of the response variables, drapability, are shown in Figures 1 and 2. Table 6 shows all the analysis reports.

\section{Design-Expert ${ }^{\circledR}$ Software}

\section{Drapeability}

Color points by value of

Drapeability:

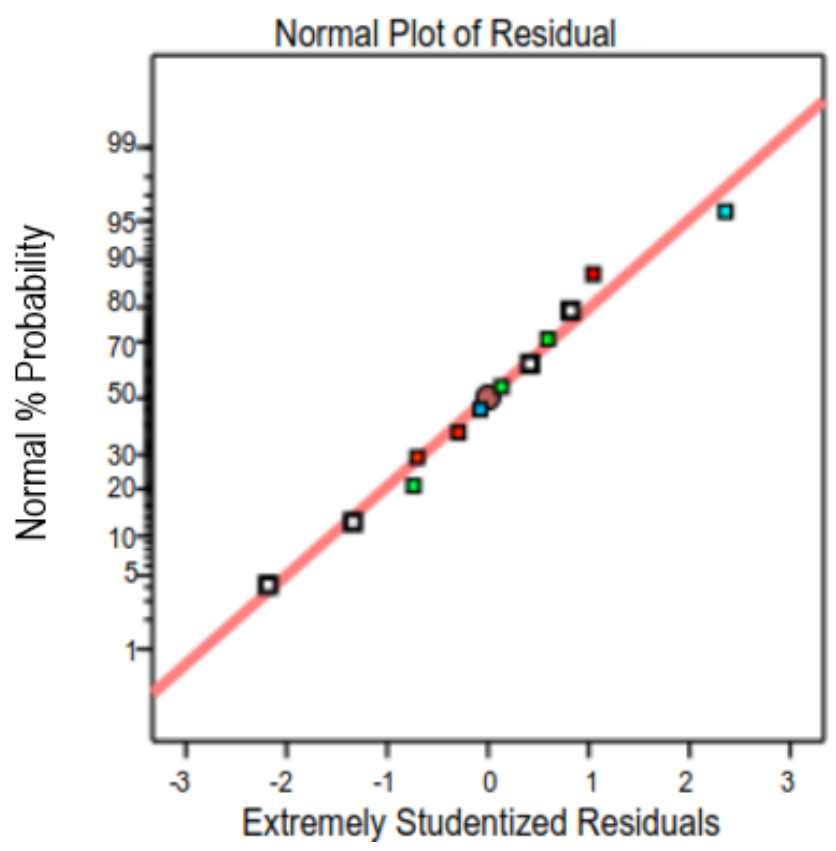

Figure 1. Data analysis for the normal plot of residuals. 
Design-Expert ${ }^{\circledR}$ Software

\section{Drapeability}

Color points by value of

Drapeability:

47.35

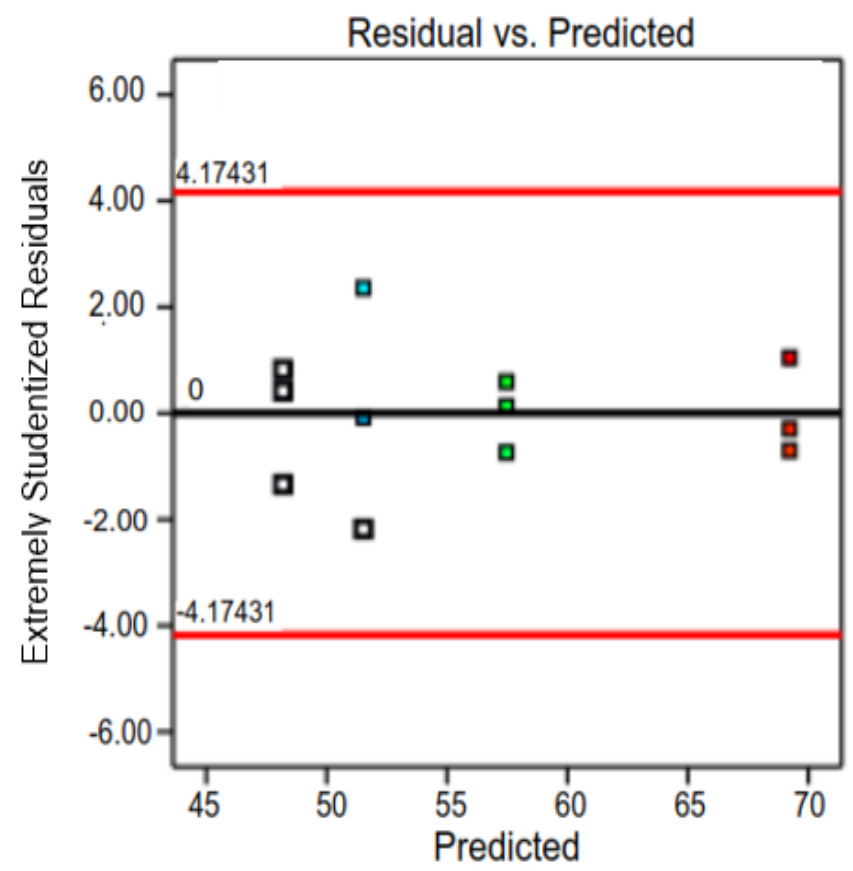

Figure 2. Residual vs. predicted analysis.

Table 6. Report of the design analysis.

\begin{tabular}{|c|c|c|c|c|c|c|c|}
\hline $\begin{array}{l}\text { Run } \\
\text { Order }\end{array}$ & $\begin{array}{c}\text { Thickness } \\
\text { (mm) }\end{array}$ & $\begin{array}{l}\text { Rigidity } \\
(\mathrm{mN} / \mathrm{mm})\end{array}$ & $\begin{array}{l}\text { Actual Value } \\
\text { of Drapability }\end{array}$ & $\begin{array}{l}\text { Value } \\
\text { Predicted of } \\
\text { Drapability }\end{array}$ & Residual & $\begin{array}{c}\text { Residuals That Have } \\
\text { Been Externally } \\
\text { Studentized }\end{array}$ & $\begin{array}{c}\text { Standard } \\
\text { Order }\end{array}$ \\
\hline 1 & 0.96 & 3.4 & 69.90 & 69.22 & 0.6767 & 1.044 & 12 \\
\hline 2 & 0.96 & 1.3 & 56.97 & 57.47 & -0.4967 & -0.740 & 8 \\
\hline 3 & 0.96 & 1.3 & 57.87 & 57.47 & 0.4033 & 0.593 & 7 \\
\hline 4 & 0.96 & 3.4 & 69.02 & 69.22 & -0.2033 & -0.294 & 10 \\
\hline 5 & 0.96 & 3.4 & 68.75 & 69.22 & -0.4733 & -0.703 & 11 \\
\hline 6 & 0.64 & 1.3 & 48.73 & 48.18 & 0.5467 & 0.821 & 2 \\
\hline 7 & 0.96 & 1.3 & 57.56 & 57.47 & 0.0933 & 0.134 & 9 \\
\hline 8 & 0.64 & 1.3 & 47.35 & 48.18 & -0.8333 & -1.340 & 3 \\
\hline 9 & 0.64 & 3.4 & 50.35 & 51.52 & -1.17 & -2.182 & 5 \\
\hline 10 & 0.64 & 1.3 & 48.47 & 48.18 & 0.2867 & 0.416 & 1 \\
\hline 11 & 0.64 & 3.4 & 52.75 & 51.52 & 1.23 & 2.357 & 6 \\
\hline 12 & 0.64 & 3.4 & 51.47 & 51.52 & -0.0533 & -0.077 & 4 \\
\hline
\end{tabular}

\subsection{The Two Factors' Interaction}

The interaction graph implies both factors have an interception at some point as the lines are not parallel, as Figure 3 shows. The graph shows the interaction; the more the thickness becomes, the more the DC. Therefore, the DC and thickness of the leather have a positive or direct relationship. The couture figure shown in Figure 4 represents whether individual factors or their interaction affect the response. Figure 4 represents how both factors' interaction influences the drapability. This can be identified by whether the couture is curved (has an effect) or a straight line (does not have an effect). 
Design-Expert? Software Factor Coding: Actual

\section{Drape Coeficient (\%)}

- Design Points

X1 = A: Rigidity

X2 = B: Thickness

B- 0.64

$\Delta \mathrm{B}+0.96$

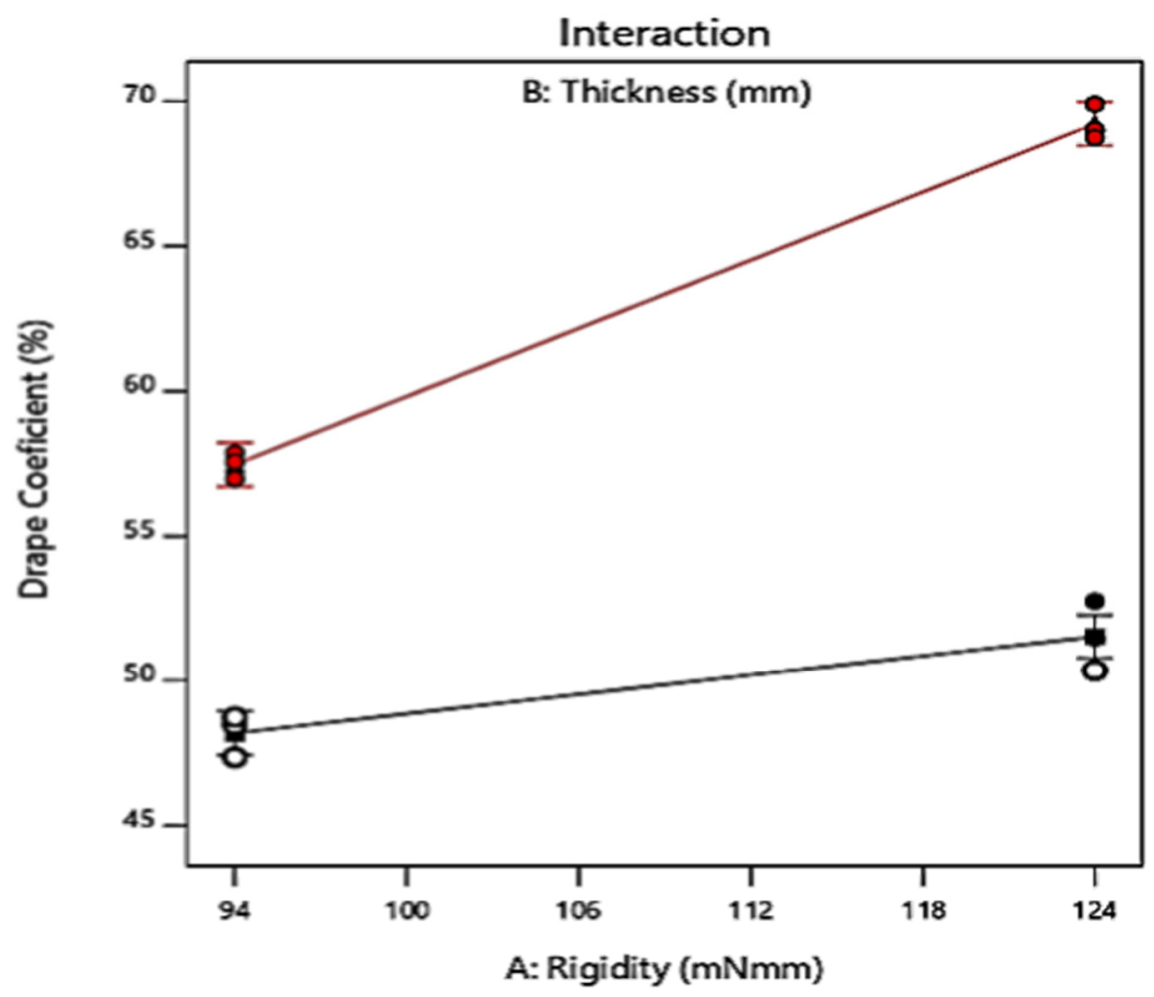

Figure 3. Interaction graph of the two independent variables.
Design-Expert ${ }^{\circ}$ Software

Factor Coding: Actual

\section{Drape Coeficient (\%)}

Design points above predicted value

Design points below predicted value

47.35

69.9

$\mathrm{X} 1=\mathbf{A}:$ Rigidity

$\mathrm{X} 2$ = B: Thickness

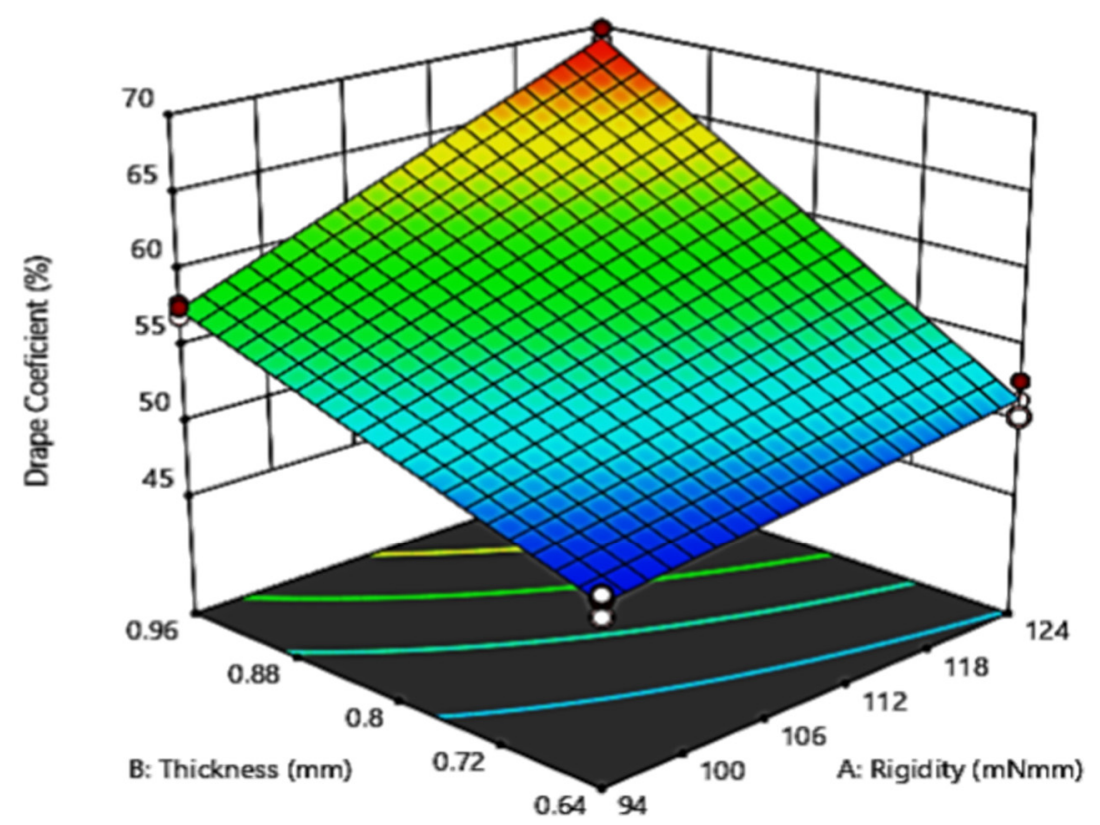

Figure 4. The three-dimensional interaction graph.

Furthermore, the interaction of both factors is important, as an ANOVA value indicates. The level of one factor affects the other factor. In addition, the two factors' interaction can be expressed by a three-dimensional graph, as Figure 4 shows. 


\subsection{Model of Regression}

The link between the response and the factors can be described in Equation (2) using the final models (in terms of coded factors).

$$
\mathrm{Y}=\mathrm{B}_{0}+\mathrm{B}_{1} \mathrm{X}_{1}+\mathrm{B}_{2} \mathrm{X}_{2}+\mathrm{B}_{12} \mathrm{X}_{1} \mathrm{X}_{2}=56.6+3.77 \mathrm{X}_{1}+6.75 \mathrm{X}_{2}+2.1 \mathrm{X}_{1} \mathrm{X}_{2}
$$

Here, $\mathrm{Y}$ is the response (drapability), $\mathrm{B}_{1}$ is factor $\mathrm{A}$ (thickness), $\mathrm{B}_{2}$ is factor $\mathrm{B}$ (rigidity), $B_{1} B_{2}$ is the interaction of $A B$ (both factors). Equation (2), in terms of coded factors, can be used to make predictions about the response for given levels of each factor. By default, the high levels of the factors are coded as +1 , and the low levels are coded as -1 . We obtained the regression model for drapability as $\mathrm{A}=+3.77, \mathrm{~B}=+6.75, \mathrm{AB}=+2.10$ with Intercept $=+56.60$. The coded equation helps identify the relative impact of the factors by comparing the factor coefficients. This equation can be useful to predict the drapeability level of sheep leather for garments with the minimum standard level of thickness and rigidity within the experimental range of thickness $(0.64-0.96 \mathrm{~mm})$ and rigidity (94-124 mN/mm).

\subsection{Response Optimization}

According to the response optimizer in Design-Expert software, the ideal factor setting is $0.64 \mathrm{~mm}$ stiffness and $94 \mathrm{mN} / \mathrm{mm}$ thickness. Therefore, the required drapability values in this study are set at 48.1833 DC, with lower and maximum bounds of $47.35 \mathrm{DC}$ and 69.9 DC, respectively, as Figure 5 shows.
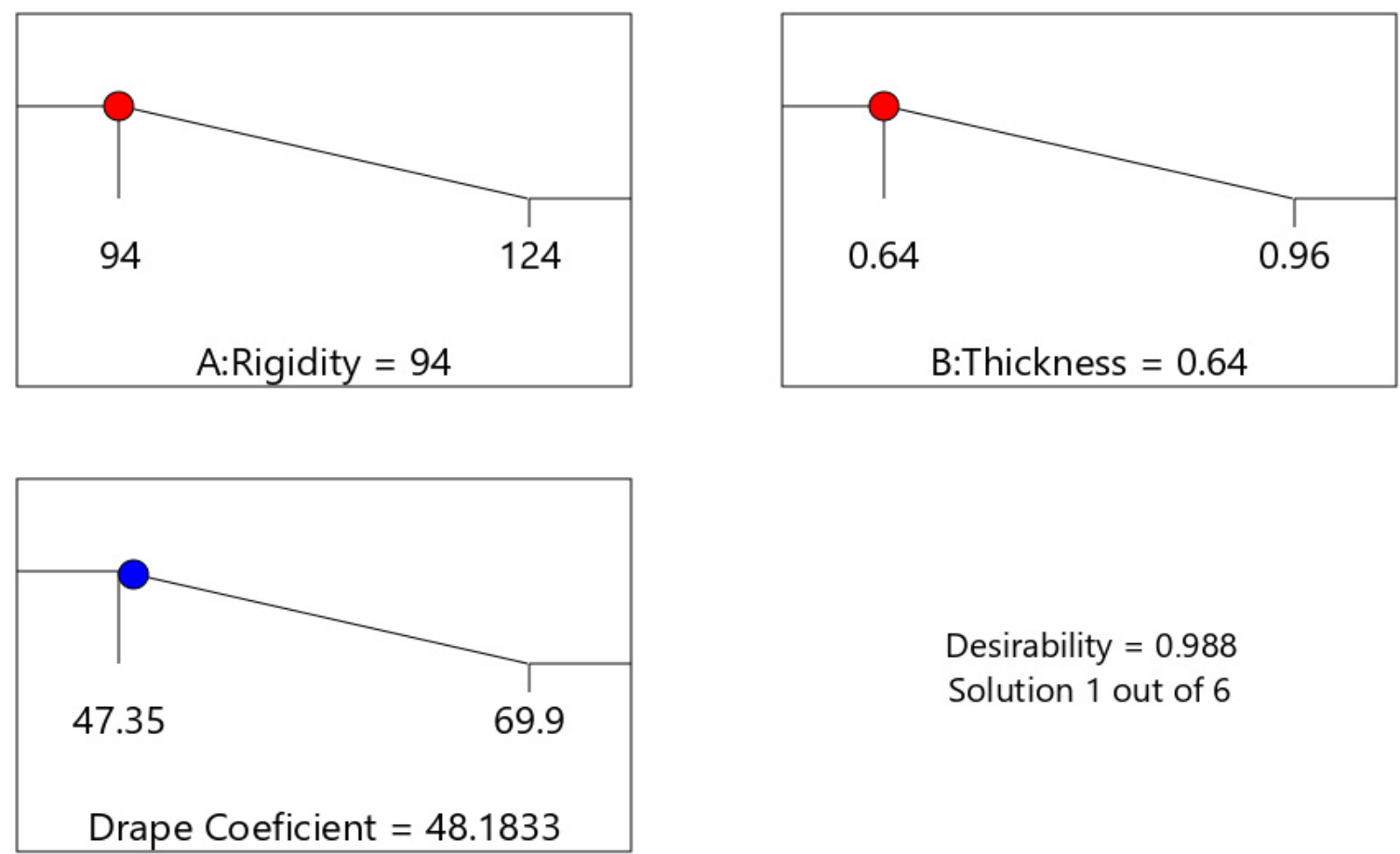

Desirability $=0.988$

Solution 1 out of 6

Figure 5. Variables optimization with lower and maximum bounds.

According to the findings of this study, the relationship between the parameters thickness and rigidity of a sample, and its resistance to drape deformation, is significantly intricate. The specimens sample leathers used in this research have a much smaller thickness and hardness than ideally upper leather (footwear leather) materials, resulting in a bigger drape when the sample is deformed in testing. As leather is not a homogeneous material, tested specimens show that the different portions of the samples have varying thicknesses and rigidities. This observation is highlighted in measuring different parts of 
the sample. Furthermore, when the four samples are examined at different levels, they reveal a substantial difference. Therefore, when the approximate pure drape model is applied to leather, significant deviations from the theoretical model are inevitable.

\section{Conclusions}

Previous studies studied thickness and rigidity, but they did not study its influence on the drape property of garment leather. This research explains the relationship between sample thickness, rigidity, and drape property and then extends the research by examining the influence of factors that could create a divergence from the ideal drape behavior. The $2^{\mathrm{k}}$ full factorial design is used in this study to determine the appropriate thickness and hardness of garment leather. The results reveal that setting the thickness and rigidity to $0.64 \mathrm{~mm}$ and $94 \mathrm{mN} / \mathrm{mm}$, respectively, is the best factor setting for the optimum level of DC of $48.1833 \%$. The DC values can be regulated to be within the required range using this optimization. So, it is possible to conclude that leathers with $0.64 \mathrm{~mm}$ thickness and $94 \mathrm{mN} / \mathrm{mm}$ rigidity level show an excellent drape that hangs straight down in many little creases and folds. It clings to a bodily part or any other object when placed over it, revealing the form of whatever is beneath it. This study can be used as a benchmark for future studies and a standard reference for clothing makers. The publication has specified the reputability of assessed drapability to reproduce the experiment for other researchers. This study also has practical implications, such as assisting practitioners in comprehending numerous elements and selecting suitable material for garment firms and customers.

Author Contributions: Conceptualization, H.M., E.B.C. and H.M.Y.; methodology, H.M. and E.B.C.; software, H.M., E.B.C. and H.M.Y.; validation, H.M., E.B.C. and H.M.Y.; formal analysis, H.M.; investigation, H.M.; resources, H.M.; data curation, H.M., E.B.C. and H.M.Y.; writing-original draft preparation, H.M., E.B.C. and H.M.Y.; writing-review and editing, H.M., and C.Z.; visualization, E.B.C. and H.M.Y.; supervision, C.Z.; project administration, H.M.Y. and C.Z.; funding acquisition, C.Z. All authors have read and agreed to the published version of the manuscript.

Funding: This research received no external funding.

Informed Consent Statement: Not applicable.

Data Availability Statement: Data can be provided by corresponding author on request.

Acknowledgments: We would like to acknowledge EiTEX leather laboratory store.

Conflicts of Interest: The authors declare no conflict of interest.

\section{References}

1. Kumar, M.P.; Fathima, N.N.; Aravindhan, R.; Rao, J.R.; Nair, B.U. An Organic Approach for Wet White Garment Leathers. J. Am. Leather Chem. Assoc. 2009, 104, 113-119.

2. Mohamed, H.A.; Van Klink, E.G.; ElHassan, S.M. Damage caused by spoilage bacteria to the structure of cattle hides and sheep skins. Int. J. Anim. Health Livest. Prod. Res. 2016, 2, 39-56.

3. Kanagaraj, J.; Senthilvelan, T.; Panda, R.C.; Kavitha, S. Eco-friendly waste management strategies for greener environment towards sustainable development in leather industry: A comprehensive review. J. Clean. Prod. 2015, 89, 1-17. [CrossRef]

4. Krishnaraj, K.; Thanikaivelan, P.; Chandrasekaran, B. Mechanical properties of sheep nappa leather influencing drape. J. Am. Leather Chem. Assoc. 2008, 103, 215-221.

5. Ork, N.; Mutlu, M.M.; Yildiz, E.Z.; Pamuk, O. Sewability properties of garment leathers tanned with various tanning materials. Ann. Univ. Oradea Fascicle Text. Leatherwork 2016, XVII, 197-202.

6. Choudhary, A.K.; Bansal, P. Drape measurement technique using manikins with the help of image analysis. In Manikins for Textile Evaluation; Woodhead Publishing Duxford, CAM: Oxford, UK, 2017; pp. 173-195.

7. Sasikala, L.; Ganesan, P.; Hariharan, S. Processing of Leather for Garments-An Overview. Man-Made Text. India 2007, 50, 356-360.

8. Eakanayake, E.; Jayamanne, S.; Wickramasinghe, W. Development of garment leather from Yellowfin tuna (Thunnusalbacares) skin. In Proceedings of the Research Symposium of UvaWellassa University, Technical Session-Sri Lanka: Aquatic Resources Technology, Badulla, Sri Lanka, 29-30 January 2015; pp. 33-35.

9. Işik, N.O.; Karavana, H.A. Determination of Some Physical Characteristics of Artificially Aged Chrome Tanned Garment Leather. Text. Appar. 2012, 22, 64-69. 
10. Cui, Y.M.; Zhong, H.; Zhu, D.H. Classify Application and Development Trend of Children Clothing Material Modeling and Style. In Proceedings of Advanced Materials Research; Trans Tech Publications Ltd.: Bäch, Switzerland, 2011; pp. 534-538.

11. Sudha, T.B.; Thanikaivelan, P.; Aaron, K.P.; Krishnaraj, K.; Chandrasekaran, B. Comfort, Chemical, Mechanical, and Structural Properties of Natural and Synthetic Leathers Used for Apparel. J. Appl. Polym. Sci. 2009, 114, 1761-1767. [CrossRef]

12. Wang, X.; Liu, X.; Deakin, C.H. Physical and mechanical testing of textiles. In Fabric Testing; Woodhead Publishing Kidlington: Oxford, UK, 2008; pp. 90-124.

13. Hu, J.; Xin, B. 2-Structure and mechanics of woven fabrics. In Structure and Mechanics of Textile Fibre Assemblies, 2nd ed.; Schwartz, P., Ed.; Woodhead Publishing: Cambridge, MA, USA, 2008; pp. 27-60.

14. Ramasubramanian, M. Physical and mechanical properties of towel and tissue. In Handbook of Physical Testing of Paper; CRC Press: Boca Raton, FL, USA, 2001; pp. 683-896.

15. Cusick, G. 46-The dependence of fabric drape on bending and shear stiffness. J. Text. Inst. Trans. 1965, 56, T596-T606. [CrossRef]

16. Krishnaraj, K.; Thanikaivelan, P.; Phebeaardn, K.; Chandrasekaran, B. Effect of sewing on the drape of goat suede apparel leathers. Int. J. Cloth. Sci. Technol. 2010, 22, 358-373. [CrossRef]

17. He, X.; Wang, Y.N.; Zhou, J.F.; Wang, H.B.; Ding, W.; Shi, B. Suitability of Pore Measurement Methods for Characterizing the Hierarchical Pore Structure of Leather. J. Am. Leather Chem. Assoc. 2019, 114, 41-47.

18. Nasr, A.; Abdelsalam, M.; Azzam, A. Effect of tanning method and region on physical and chemical properties of barki sheep leather. Egypt. J. Sheep Goat Sci. 2013, 8, 123-130. [CrossRef]

19. Howes, F.N. Vegetable tanning materials. Veg. Tann. Mater. 1953, XI, 325. [CrossRef]

20. Covington, A. The chemistry of tanning materials. In Conservation of Leather and Related Materials; Routledge: London, UK, 2005; pp. $44-57$.

21. Jaynes, J.; Ding, X.; Xu, H.; Wong, W.K.; Ho, C.M. Application of fractional factorial designs to study drug combinations. Stat. Med. 2013, 32, 307-318. [CrossRef] [PubMed]

22. Box, G.; Bisgaard, S.; Fung, C. An explanation and critique of Taguchi's contributions to quality engineering. Qual. Reliab. Eng. Int. 1988, 4, 123-131. [CrossRef]

23. Haines, B.; Barlow, J. The anatomy of leather. J. Mater. Sci. 1975, 10, 525-538. [CrossRef]

24. Abdin, Y.; Taha, I.; El-Sabbagh, A.; Ebeid, S. Description of draping behaviour of woven fabrics over single curvatures by image processing and simulation techniques. Compos. Part B Eng. 2013, 45, 792-799. [CrossRef]

25. Zhou, N.; Ghosh, T.K. On-line measurement of fabric bending behavior: Part II: Effects of fabric nonlinear bending behavior. Text. Res. J. 1998, 68, 533-542. [CrossRef]

26. Xu, G.; Wilson, K.S.; Okamoto, R.J.; Shao, J.Y.; Dutcher, S.K.; Bayly, P.V. Flexural Rigidity and Shear Stiffness of Flagella Estimated from Induced Bends and Counterbends. Biophys. J. 2016, 110, 2759-2768. [CrossRef]

27. Phebe, K.; Thanikaivelan, P.; Krishnaraj, K.; Chandrasekaran, B. Factors Influencing the Seam Efficiency of Goat Nappa Leathers. J. Am. Leather Chem. Assoc. 2012, 107, 78-84.

28. Ukey, P.; Kadole, P. Characterizations of bottom wear fabrics for drapability. Man-Made Text. India 2020, $48,15-17$.

29. Maki, J.M.; Wetzel, J.E.; Wichiramala, W. Drapeability. Discret. Comput. Geom. 2005, 34, 637-657. [CrossRef]

30. Hunter, L.; Fan, J.; Chau, D. Fabric and garment drape. In Engineering Apparel Fabrics and Garments; CRC Press: Boca Raton, FL, USA, 2009; pp. 102-130. 